\title{
Pengaruh Kohesivitas Kelompok Dan Kepuasan Kerja Terhadap Kinerja Karyawan Pada PT Sapadia Wisata Rantauprapat
}

\author{
Siti Lam'ah Nasution \\ Dosen Fakultas Ekonomi dan Bisnis (FEB), Universitas Labuhanbatu \\ Email: sitinasution81@gmail.com
}

\begin{abstract}
Abstrak
Penelitian ini bertujuan untuk mengetahui Pengaruh Kohesivitas Kelompok Dan Kepuasan Kerja Terhadap Kinerja Karyawan Pada PT. Sapadia Wisata Rantauprapat. Jenis Penelitian Ini Adalah Penelitian Asosiatif. Pengumpulan Data Dalam Penelitian ini dilakukan melalui pendekatan survey dengan jenis penelitian deskriptif kuantitatif dengan menyebar kuesioner kepada 30 responden, sedangkan populasi yang dijadikan dalam penelitian ini adalah Karyawan PT. Sapadia Wisata Rantauprapat. Teknik pengumpulan data dilakukan dengan wawancara, kuesioner dan studi dokumentasi. Alat analisis data yang digunakan pada penelitian ini menggunakan SPSS (Statistical Product Sofware Solution). Teknik analisis data dalam penelitian ini adalah analisis deskriptif, analisis regresi linear berganda, pengujian hipotesis dengan menggunakan uji signifikan parsial (uji t), pengujian signifikan simultan (uji $F$ ), dan pengujian koefisien determinasi $\left(R^{2}\right)$. Hasil penelitian ini menunjukkan secara parsial (uji t) diketahui bahwa Kohesivitas Kelompok berpengaruh signifkan terhadap Kinerja Karyawan Pada PT. Sapadia Wisata Rantauprapat. Kemudian Kepuasan Kerja berpengaruh signifkan terhadap Kinerja Karyawan Pada PT. Sapadia Wisata Rantauprapat. Pada pengujian secara simultan (uji F) diketahui bahwa Kohesivitas Kelompok Dan Kepuasan Kerja berpengaruh signifkan terhadap Kinerja Karyawan Pada PT. Sapadia Wisata Rantauprapat. Melalui pengujian koefisien determinasi (R Square) sebesar 0,521 berarti 52,1\% faktor-faktor Kinerja Karyawan Pada PT. Sapadia Wisata Rantauprapat dapat dijelaskan oleh Kohesivitas Kelompok Dan Kepuasan Kerja sedangkan sisanya 47,9\% dapat dijelaskan oleh faktor-faktor lain yang tidak diteliti dalam penelitian ini.
\end{abstract}

\section{Kata Kunci: Kohesivitas Kelompok, Kepuasan Kerja, Kinerja Karyawan .}

\begin{abstract}
This study aims to determine the effect of group cohesiveness and job satisfaction on employee performance at PT. Sapadia Wisata Rantauprapat. This type of research is associative research. Data collection in this study was conducted through a survey approach with quantitative descriptive research type by distributing questionnaires to 30 respondents, while the population used in this study were employees of PT. Sapadia Wisata Rantauprapat. The data collection technique is done by interview, questionnaire and documentation study. The data analysis tool used in this study was SPSS (Statistical Product Software Solution). The data analysis technique in this research is descriptive analysis, multiple linear regression analysis, hypothesis testing using partial significance test ( $t$ test), simultaneous significance testing ( $F$ test), and determination coefficient testing ( $R 2)$. The results of this study indicate partially ( $t$ test) it is known that group cohesiveness has a significant effect on employee performance at PT. Sapadia Wisata Rantauprapat. Then Job Satisfaction has a significant effect on Employee Performance at PT. Sapadia Wisata Rantauprapat. In simultaneous testing (F test) it is known that Group Cohesivity and Job Satisfaction have a
\end{abstract}


significant effect on Employee Performance at PT. Sapadia Wisata Rantauprapat. Through testing the coefficient of determination ( $R$ Square) of 0.521 means $52.1 \%$ of Employee Performance factors at PT. Sapadia Wisata Rantauprapat can be explained by Group Cohesivity and Job Satisfaction while the remaining 47.9\% can be explained by other factors which were not examined in this study.

\section{Keywords: Group Cohesivity, Job Satisfaction, Employee Performance.}

\section{PENDAHULUAN}

\subsection{Latar Belakang Masalah}

Sumber daya manusia merupakan salah satu aset yang paling penting di dalam sebuah perusahaan, karena kunci keberhasilan perusahaan berawal dari kegiatan pemberdayaan sumber daya manusia yaitu orang-orang yang menyediakan tenaga, bakat kreativitas dan semangat bagi perusahaan sebagai roda penggerak utama pada suatu perusahaan. Apapun bidang usaha yang dijalankan perusahaan, sumber daya manusia akan berperan dalam hasil akhir perusahaan tersebut. Oleh karena itu sumber daya manusia yang handal dan berkompeten sangat dibutuhkan bagi sebuah perusahaan. Upaya yang dilakukan dalam pencapaian tujuan perusahaan yang sekaligus dapat menunjang karyawan dalam memenuhi kebutuhan hidup mereka diantaranya adalah dengan memberikan kohesivitas kelompok dan kepuasan kerja untuk mendorong para karyawan mencapai kinerja.

PT Sapadia Wisata Rantauprapat atau dikenal Boombara Waterpark bergerak dalam bidang Wisata Air dan Hiburan Keluarga. Saat ini, Boombara Waterpark menjadi objek wisata rekreasi air terbesar di Rantauprapat karena tersedia berbagai wahana air yang seru menyenangkan, dan untuk ke depannya berencana akan terus melakukan pembangunan dalam rangka pengembangan Boombara Water Park.
Untuk itu pemenuhan kohesivitas kelompok dan kepuasan kerja kepada karyawan sangat diperlukan dalam menunjang kinerja yang optimal agar Boombara Waterpark menjadi lebih berkembang di Kota Rantauprapat Labuhanbatu.

Pada dasarnya kinerja karyawan merupakan hasil proses yang kompleks, baik berasal dari diri pribadi karyawan (internal factor) maupun upaya strategis dari perusahaan. Kinerja yang baik tentu saja merupakan harapan bagi semua perusahaan dan institusi yang mempekerjakan karyawan. Kinerja termasuk cerminan dari pekerjaanpekerjaan individu, dimana setiap individu yang bekerja dengan baik, dan mampu memberikan kontribusi terbaik mereka merupakan jawaban dari berhasil atau tidaknya tujuan organisasi yang telah ditetapkan. Kinerja juga dapat diukur dari kemampuan suatu organisasi untuk melakukan tugas pokoknya sesuai dengan ketentuan yang telah ditetapkan. Setiap proses kegiatan dan kelembagaan diarahkan untuk menghasilkan sesuatu yang benar-benar sesuai dengan kebutuhan melalui pemanfaatan yang sebaik-baiknya dengan berbagai sumber yang tersedia.

Berdasarkan Survey yang dilakukan penulis di PT. Sapadia Wisata Rantauprapat, permasalahan mengenai kinerja yang dihasilkan oleh para karyawan masih kurang maksimal dalam pemenuhan pencapaian tujuan yang telah ditetapkan oleh perusahaan. Hal ini disebabkan karena kesempatan untuk 
berpartisipasi dalam organisasi, dan kualitas interaksi antar anggota organisasi.para karyawan belum terpenuhi dengan baik. Masih banyak karyawan yang tidak menekuni bidang pekerjaannya dan tidak menjalankan tugas dan tanggung jawabnya sebagaimana mestinya yang menyebabkan tingkat kompleksitas perusahaan dalam menjalankan fungsinya tidak dapat berjalan lancar dan berhasil dengan baik sesuai pencapaian tujuan.

\section{TINJAUAN PUSTAKA}

\subsection{Kohevisitas Kelompok}

Menurut George \& Jones (2012) kohevisitas kelompok adalah anggota kelompok yang memiliki daya tarik satu sama lain. Kelompok kerja yang kohesivitasnya tinggi adalah saling tertarik pada setiap anggota, kelompok kerja merupakan perasaan daya tarik individu terhadap kelompok dan memotivasi mereka tetap bersama kelompok dimana hal tersebut menjadi faktor penting dalam keberhasilan kelompok.

Robbins (2011) menyatakan bahwa kohesivitas kelompok adalah sejauh mana anggota merasa tertarik satu sama lain dan termotivasi untuk tetap berada dalam kelompok tersebut, Misalnya, karyawan suatu kelompok kerja yangkompak karena menghabiskan bnyak waktu bersama, atau kelompok yang berukuran kecil menyediakan sarana interaksi yang lebih intensif, atau kelompok yang telah berpengalaman dlam mengahadapi anacman dari luar menyebabkan anggotanya lebih dekat satu sama lain.

\subsection{Kepuasan Kerja}

Kepuasan kerja karywan harus diciptakan sebaik-baiknya supaya moral kerja, dedikasi, kecintaan dan kedisiplinan karyawan meningkat. Oleh karna itu kepuasan kerja karyawan sangat penting dan merupakan kunci pendorong moral, kedisiplinan, prestasi kerja karyawan meningkat. Oleh karna itu kepuasan kerja karyawan sangat penting dan merupakan kunci pendorong moral, kedisiplinan prestasi kerja karyawan dalam mendukung terwujudnya tujuan perusahaan. Robbins (2011) mengatakan bahwa kepuasan kerja adalah sikap umum terhadap pekerja seorang, yang menunjukkan perbedaan antara jumlah yang mereka yakni seharunya mereka terima. Pandangan senada dikemukakan oleh Gibson, Ivancenvich, dan Donely (2012) yang menyatakan kepuasan kerja sebagai sikap yang dimiliki pekerja tentang pekerjaan mereka.

\subsection{Kinerja Karyawan}

Kinerja karyawan menurut Mathis dan Jackson (2011) adalah apa yang dilakukan atau tidak dilakukan oleh pegawai yang meliputi kuantitas dari hasil, kualitas dari hasil, ketepatan waktu dari hasil, kehadiran dan kemampuan bekerja sama. Bernardin dan Russel dalam Wahab (2012) dalam mengukur kinerja pegawai dipergunakan sebuah daftar pertanyaan yang berisikan beberapa dimensi kriteria tentang hasil kerja.

\subsection{Kerangka Konseptual}

Kerangka konseptual dari penelitian ini adalah:

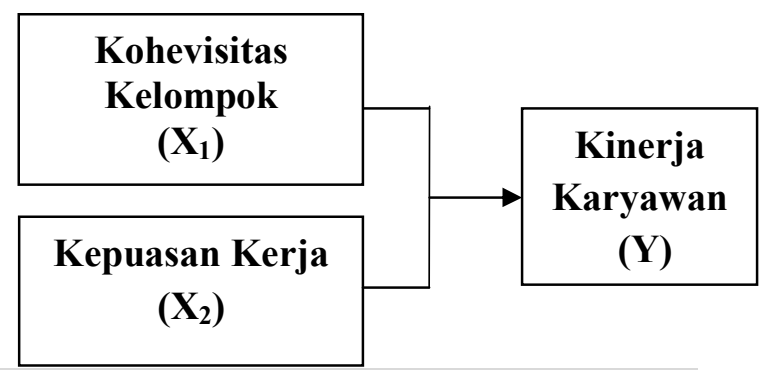

$114 \mid \mathrm{P}$ a g e 


\section{Gambar 2.1. Kerangka Konseptual}

\section{METODE PENELITIAN}

\subsection{Jenis Penelitian}

Jenis penelitian yang digunakan dalam penelitian ini adalah penelitian assosiatif, yakni penelitian yang menghubungkan antara dua variabel atau lebih Sugiyono (2010). Dengan hubungan kausal yaitu hubungan yang bersifat sebab akibat Sugiyono (2010). Tempat dan waktu penelitian ini dilakukan pada PT. Sapadia Wisata Rantauprapat, Jl. H. Adam Malik by Pass/ Jl. Baru Rantauprapat, Kabupaten Labuhanbatu.

\subsection{Batasan Operasional}

Batasan operasional variabel digunakan untuk menghindari kesimpangsiuran dalam membahas dan menganalisa permasalahan dalam penelitian ini. Oleh karena itu, dibuat suatu batasan operasional antara lain:

1. Variabel bebas (Independent Variable) terdiri dari:

Kohevisitas Kelompok (X1), Kepuasan Kerja (X2).

2. Variabel terikat (Dependent Variable) terdiri dari:

Kinerja Karyawan (Y)

\subsection{Populasi dan Sampel}

Populasi yang diambil dalam penelitian ini adalah menggunakan teknik pengambilan sampel menggunakan sensus dan mengambil sampel dari seluruh populasi (sampel jenuh) sebanyak 30 orang.

\subsection{Jenis Data dan Sumber Data}

Menurut Situmorang dan Lutfi (2014) cara memperolehnya data terbagi dua berdasar pada sumbernya yaitu: 1) Data primer (Primary Data) yaitu data yang dikumpulkan sendiri oleh perorangan/suatu organisasi secara langsung dari objek yang diteliti dan untuk kepentingan studi yang bersangkutan yang dapat berupa interview, kuesioner dan observasi. Data primer diperoleh dengan memberikan daftar pertanyaan (kuesioner) kepada karyawan PT. Sapadia Wisata Rantauprapat. 2) Data sekunder (Secondary Data) yaitu data yang diperoleh atau dikumpulkan dan disatukan oleh studi-studi sebelumnya atau yang diterbitkan oleh berbagai instansi lain. Biasanya sumber tidak langsung berupa data dokumentasi dan arsip-arsip resmi.

\subsection{Metode dan Teknik Pengumpulan Data}

Dalam penelitian ini, metode pengumpulan data yang digunakan adalah metode kuesioner, jenis kuesioner ini adalah kuesioner tertutup dengan skala likert. Teknik pengumpulan data dalam penelitian ini adalah kuesioner dan wawancara. Menurut Sugiyono (2010), teknik pengumpulan data meliputi:

a. Wawancara (Interview), digunakan sebagai teknik pengumpulan data apabila peneliti ingin melakukan studi pendahuluan untuk menemukan permasalah yang harus diteliti, dan juga apabila peneliti ingin mengetahui hal-hal dari responden yang lebih mendala dan jumlah respondennya sedikit atau kecil. Teknik pengumpulan data ini mendasarkan diri pada laporan tentang diri sendiri atau self report, atau setidak-tidaknya pada pengetahuan atau keyakinan pribadi.

b. Kuesioner, merupakan teknik pengumpulan data yang dilakukan dengan cara memberi seperangkat pertanyaan atau pernyataan tertulis kepada responden untuk dijawabnya. Kuesioner merupakan teknik pengumpulan data yang efisien bila peneliti tahu dengan pasti variable yang akan diukur dan tahu apa yang bisa diharapkan dari responden. Selain 
itu kuesioner juga cocok digunakan bila jumlah responden cukup besar dan tersebar di wilayah yang luas. Kuesioner dapat berupa pertanyaan/pernyataan tertutup atau terbuka, dapat diberikan kepada responden secara langsung atau dikirim melalui pos atau internet.

\section{HASIL PENELITIAN DAN PEMBAHASAN}

\subsection{Analisis Regresi Linear Berganda}

Metode analisis data yang digunakan dalam penelitian ini dengan mengumpulkan, mengolah, mengklasifikasikan dan menginterprestasikan data penelitian, sehingga diperoleh gambaran jelas mengenai objek yang diteliti dengan menggunakan Analisis Regresi Linier Berganda. Menurut Situmorang dan Lufti (2014) mengemukakan analisis regresi linear berganda ditujukan untuk menentukan hubungan linear antar beberapa variabel independen yaitu Kohevisitas Kelompok $\left(\mathrm{X}_{1}\right)$, dan Kepuasan Kerja $\left(\mathrm{X}_{2}\right)$ dengan variabel dependen yaitu Kinerja Karyawan (Y).. Perhitungan persamaan regresi linear berganda adalah sebagai berikut :

$$
\mathbf{Y}=\mathbf{a}+\mathbf{b}_{1} \mathbf{X}_{1}+\mathbf{b}_{2} \mathbf{X}_{2}+\mathbf{e}
$$

\subsection{Uji Signifikan Secara Parsial (Uji-t)}

Untuk menguji apakah hipotesis yang diajukan diterima atau ditolak digunakan statistik t (uji t). Pengujian ini dilakukan untuk mengetahui seberapa besar pengaruh variabel bebas yaitu Kohevisitas Kelompok $\left(\mathrm{X}_{1}\right)$, dan Kepuasan Kerja $\left(\mathrm{X}_{2}\right)$, secara parsial terhadap variabel terikat yaitu Kinerja Karyawan (Y). Uji parsial (uji t) dapat dilihat pada tabel berikut:
Tabel 4.1

Hasil Uji Parsial (Uji t)

\begin{tabular}{|c|c|c|c|c|c|}
\hline \multirow{3}{*}{ Model } & \multirow{2}{*}{\multicolumn{2}{|c|}{$\begin{array}{l}\text { Unstandardized } \\
\text { Coefficients }\end{array}$}} & \multirow{3}{*}{$\begin{array}{l}\text { Standa } \\
\text { rdized } \\
\text { Coeffi } \\
\text { cients } \\
\text { Beta }\end{array}$} & \multirow{3}{*}{$\mathbf{t}$} & \multirow{3}{*}{ Sig. } \\
\hline & & & & & \\
\hline & B & $\begin{array}{l}\text { Std. } \\
\text { Error }\end{array}$ & & & \\
\hline \multirow{3}{*}{\begin{tabular}{|ll} 
& (Constant) \\
& Kohevisitas \\
1 & Kelompok
\end{tabular}} & 9,509 & 3,175 & & 2,995 & ,006 \\
\hline & 403, & 205 & 357, & 1,968 & ,059 \\
\hline & ,547 & ,230 & ,430 & 2,373 & ,025 \\
\hline
\end{tabular}

a. Dependent Variable: Kinerja Karyawan

Sumber: Hasil Penelitian, 2020

Berdasarkan Tabel 4.1 terlihat bahwa nilai $t_{\text {hitung }}$ untuk variabel Kohevisitas Kelompok $\left(\mathrm{X}_{1}\right)$ sebesar 1,968, dan Kepuasan Kerja $\left(\mathrm{X}_{2}\right)$ sebesar 2,373 dengan nilai signifikan untuk masing-masing variabel independen $(0,059) ;(0,025)$, Sedangkan untuk nilai $t_{\text {tabel }}$ pada tabel statistik distribusi t dengan level of test $\alpha=$ $5 \%$ dan $\mathrm{df}_{1}=(\mathrm{k}-1)=2$ dan $\mathrm{df}_{2}=(\mathrm{n}-\mathrm{k}-1)=$ 27 sebesar 1,703. Berdasarkan kriteria bahwa jika nilai $t_{\text {hitung }}>t_{\text {tabel }}$ yakni $(1,968>$ $1,703) ;(2,373>1,703)$, dapat disimpulkan bahwa variabel Kohevisitas Kelompok $\left(\mathrm{X}_{1}\right)$, dan Kepuasan Kerja $\left(\mathrm{X}_{2}\right)$, berpengaruh positif dan signifikan terhadap Kinerja Karyawan (Y) pada PT. Sapadia Wisata Rantauprapat.

\subsection{Uji Signifikan Secara Serempak (Uji-F)}

Untuk menguji apakah hipotesis yang diajukan diterima atau ditolak digunakan uji $\mathrm{F}$. Uji $\mathrm{F}$ bertujuan untuk mengetahui pengaruh secara serentak atau bersama-sama variabel bebas yaitu Kohevisitas Kelompok $\left(\mathrm{X}_{1}\right)$, dan Kepuasan Kerja $\left(\mathrm{X}_{2}\right)$, terhadap variabel terikat Kinerja Karyawan (Y). Mencari nilai $F_{\text {hitung dengan menggunakan Tabel } 4.2}$ ANOVA dari hasil pengolahan SPSS sebagai berikut: 
Tabel 4.2

Hasil Uji Simultan (Uji F)

\begin{tabular}{|c|c|c|c|c|c|}
\hline Model & $\begin{array}{l}\text { Sum of } \\
\text { Squares }\end{array}$ & $\mathrm{df}$ & $\begin{array}{l}\text { Mean } \\
\text { Square }\end{array}$ & $\mathbf{F}$ & Sig. \\
\hline Regression & 101,856 & 2 & 50,928 & 14,705 &, $000^{\mathrm{b}}$ \\
\hline 1 Residual & 93,511 & 27 & 3,463 & & \\
\hline Total & 195,367 & 29 & & & \\
\hline
\end{tabular}

Berdasarkan Tabel $\quad 4.2$ menunjukkan bahwa hasil uji $\mathrm{F}$ sebesar 14,705 dengan tingkat signifikan sebesar 0.000 sedangkan nilai $F_{\text {tabel }}$ pada tabel statistik distribusi t dengan level of test $\alpha=$ $5 \%$ dan $\mathrm{df}_{1}=(\mathrm{k}-1)=2$ dan $\mathrm{df}_{2}=(\mathrm{n}-\mathrm{k}-1)=$ 27 sebesar 3,354. Jika dibandingkan nilai $F_{\text {hitung }}(14,705)>F_{\text {tabel }}(3,354)$ maka disimpulkan bahwa secara bersama-sama variabel Kohevisitas Kelompok $\left(\mathrm{X}_{1}\right)$, dan Kepuasan Kerja $\left(\mathrm{X}_{2}\right)$ berpangaruh positif dan signifikan terhadap Kierja Karyawan (Y) pada PT. Sapadia Wisata Rantauprapat

\subsection{Pembahasan Hasil Penelitian}

\section{Pengaruh Kohevisitas Kelompok Terhadap Kierja Karyawan}

Hasil hipotesis penelitian diperoleh bahwa variabel Kohevisitas Kelompok $\left(X_{1}\right)$ memiliki nilai $t_{\text {hitung }}$ sebesar 1,968 , dengan nilai signifikan $(0,059)$, Sedangkan untuk nilai $t_{\text {tabel }}$ pada tabel statistik distribusi t dengan level of test $\alpha=5 \%$ dan $\mathrm{df}_{1}=(\mathrm{k}-1)=2$ dan $\mathrm{df}_{2}=(\mathrm{n}-\mathrm{k}-1)=27$ sebesar 1,703. Berdasarkan kriteria bahwa jika nilai $t_{\text {hitung }}>t_{\text {tabel }}$ yakni $(1,968>1,703)$ dapat disimpulkan bahwa variabel Kohevisitas Kelompok $\left(\mathrm{X}_{1}\right)$, berpengaruh positif dan signifikan terhadap Kinerja Karyawan (Y) pada PT. Sapadia Wisata Rantauprapat pada $\alpha=5 \%$.

Hasil penelitian ini mendukung teori sebelumnya yang dikemukakan oleh George \& Jones (2012) kohevisitas kelompok adalah anggota kelompok yang memiliki daya tarik satu sama lain.
Kelompok kerja yang kohesivitasnya tinggi adalah saling tertarik pada setiap anggota, kelompok kerja merupakan perasaan daya tarik individu terhadap kelompok dan memotivasi mereka tetap bersama kelompok dimana hal tersebut menjadi faktor penting dalam keberhasilan kelompok.

Hal ini juga sesuai dengan penelitian sebelumnya salah satunya adalah penelitian yang dilakukan Malik (2017) dengan judul penelitian Pengaruh Kohesivitas Kelompok Terhadap Kinerja Karyawan Pada PT. Kerta Rajasa Raya Kabupaten Sidoarjo. Hasil menunjukkan Kohesifitas Kelompok memberikan pengaruh positif terhadap Kinerja karyawan pada PT Kerta Rajasa Raya Kab Sidoarjo. Maka semakin tinggi kohesifitas yang ada pada karyawan maka akan berdampak kepada semakin tinggi pula kinerja karyawan yang ada pada PT Kerta Rajasa Raya Kabupaten Sidoarjo.

\section{Pengaruh Kepuasan Kerja Terhadap Kierja Karyawan}

Hasil hipotesis penelitian diperoleh bahwa nilai $t_{\text {hitung }}$ untuk Variabel Kepuasan Kerja $\left(\mathrm{X}_{2}\right)$ sebesar 2,373 dengan nilai signifikan $(0,025)$, Sedangkan untuk nilai $\mathrm{t}_{\text {tabel }}$ pada tabel statistik distribusi $\mathrm{t}$ dengan level of test $\alpha=5 \%$ dan $\mathrm{df}_{1}=(\mathrm{k}-1)=2$ dan $\mathrm{df}_{2}=(\mathrm{n}-\mathrm{k}-1)=27$ sebesar 1,703. Berdasarkan kriteria bahwa jika nilai $t_{\text {hitung }}>t_{\text {tabel }}$ yakni $(2,373>1,703)$, dapat disimpulkan bahwa variabel Kepuasan Kerja $\left(\mathrm{X}_{2}\right)$, berpengaruh positif dan signifikan terhadap Kinerja Karyawan (Y) pada PT. Sapadia Wisata Rantauprapat.pada $\alpha=5 \%$.

Hasil penelitian ini mendukung teori sebelumnya yang dikemukakan oleh Robbins (2011) mengatakan bahwa kepuasan kerja adalah sikap umum terhadap pekerja seorang, yang menunjukkan perbedaan antara jumlah 
yang mereka yakni seharunya mereka terima.

Hal ini juga sesuai dengan penelitian sebelumnya salah satunya adalah penelitian yang dilakukan Susanto (2019) Dengan Judul "Pengaruh Motivasi Kerja, Kepuasan Kerja, Dan Disiplin Kerja Terhadap Kinerja Karyawan Pada Divisi Penjualan PT Rembaka”. Hasil penelitian menunjukkan bahwa motivasi kerja memiliki pengaruh terhadap kinerja karyawan, kepuasan kerja memiliki pengaruh terhadap kinerja karyawan, disiplin kerja memiliki pengaruh terhadap kinerja karyawan.

\section{Pengaruh Kohevisitas Kelompok dan Kepuasan Kerja Terhadap Kierja Karyawan \\ Berdasarkan hasil penelitian bahwa} hasil uji $F$ sebesar 14,705 dengan tingkat signifikan sebesar 0.000 sedangkan nilai $\mathrm{F}_{\text {tabel }}$ pada tabel statistik distribusi $\mathrm{t}$ dengan level of test $\alpha=5 \%$ dan $\mathrm{df}_{1}=(\mathrm{k}-1)$ $=2$ dan $\mathrm{df}_{2}=(\mathrm{n}-\mathrm{k}-1)=27$ sebesar 3,354. Jika dibandingkan nilai $F_{\text {hitung }}(14,705)>$ $F_{\text {tabel }}(3,354)$ maka disimpulkan bahwa secara bersama-sama variabel Kohevisitas Kelompok $\left(\mathrm{X}_{1}\right)$, dan Kepuasan Kerja $\left(\mathrm{X}_{2}\right)$ berpangaruh positif dan signifikan terhadap Kierja Karyawan (Y) pada PT. Sapadia Wisata Rantauprapat.

\section{KESIMPULAN DAN SARAN}

\subsection{Kesimpulan}

Kesimpulan yang dirumuskan penulis dalam penelitian dengan judul "Pengaruh Kohesivitas Kelompok Dan Kepuasan Kerja Terhadap Kinerja Karyawan Pada PT. Sapadia Wisata Rantauprapat" adalah:

1. Secara parsial Kohesivitas Kelompok berpengaruh signifikan terhadap Kinerja Karyawan pada PT. Sapadia Wisata Rantauprapat. Dimana Kohesivitas Kelompok memiliki nilai $\mathrm{t}$ hitung sebesar 1,968, dengan nilai signifikan (0,059), Sedangkan untuk nilai $t_{\text {tabel }}$ pada tabel statistik distribusi $\mathrm{t}$ dengan level of test $\alpha=5 \%$ dan $\mathrm{df}_{1}=(\mathrm{k}$ 1) $=2$ dan $\mathrm{df}_{2}=(\mathrm{n}-\mathrm{k}-1)=27$ sebesar 1,703 .

2. Secara parsial Kepuasan Kerja berpengaruh signifikan terhadap Kinerja Karyawan pada PT. Sapadia Wisata Rantauprapat. Dimana Kepuasan Kerja $\left(\mathrm{X}_{2}\right)$ memiliki nilai $\mathrm{t}$ hitung sebesar sebesar 2,373, dengan nilai signifikan $(0,025)$, Sedangkan untuk nilai $t_{\text {tabel }}$ pada tabel statistik distribusi $\mathrm{t}$ dengan level of test $\alpha=5 \%$ dan $\mathrm{df}_{1}=(\mathrm{k}$ 1) $=2$ dan $\mathrm{df}_{2}=(\mathrm{n}-\mathrm{k}-1)=27$ sebesar 1,703 .

3. Secara Simultan Kohesivitas Kelompok dan Kepuasan Kerja berpengaruh signifikan terhadap Kinerja Karyawan pada PT. Sapadia Wisata Rantauprapat Dengan hasil uji F sebesar 14,705 dan tingkat signifikan sebesar 0.000 sedangkan nilai $\mathrm{F}_{\text {tabel }}$ pada tabel statistik distribusi t dengan level of test $\alpha=5 \%$ dan $\mathrm{df}_{1}=(\mathrm{k}-1)=2$ dan $\mathrm{df}_{2}=(\mathrm{n}-\mathrm{k}-1)=$ 27 sebesar 3,354.

\section{DAFTAR PUSTAKA}

[1] George, Jennifer and Gareth $\mathrm{R}$ Jones. (2012). Understanding and Managing Organizational Behavior. Pearson Education, Inc, New Jersey.

[2] Gibson, James., L., Jhon M., Ivancevich., dan H., Donnelly., Jr. 2012: Organisasi dan Manajemen, Perilaku, Struktur, dan proses, terjemahan oleh Joerban Wahid, Erlangga, Jakarta.

[3] Mathis Robert L dan Jackson John H. 2011. Human Resource Management, Edisi 10, Jakarta: Salemba Empat.

[4] Malik Abdul, 2017. "Pengaruh Kohesivitas Kelompok Terhadap 
Kinerja Karyawan Pada PT. Kerta Rajasa Raya Kabupaten Sidoarjo". Jurnal Ilmu Manajemen Volume 5 Nomor 4- Jurusan Manajemen Fakultas Ekonomi Universitas Negeri Surabaya.

[5] Robbins, Stepeh p.2011. Perilaku Organisasi. Edisi 10. Jakarta: Erlangga.

[6] Susanto Natalia, 2019. "Pengaruh Motivasi Kerja, Kepuasan Kerja, Dan Disiplin Kerja Terhadap Kinerja Karyawan Pada Divisi Penjualan PT Rembaka”. Jurnal Program Studi Manajemen, Fakultas Ekonomi, Universitas Kristen Petra. AGORA Vol. 7, No. 1.

[7] Situmorang dan Lufti, 2014. Analisis Data untuk Riset Manajemen dan Bisnis, USU Press, Medan.

[8] Sugiyono, 2010. Metode Penelitian Kuantitatif kualitatif dan $R \& D$, Alfabeta, Bandung.

[9] Wahab, Abdul Solichin. 2012. Analisis Kebijaksanaan dari Formulasi ke Implementasi Kebijaksanaan Negara. Jakarta: Bumi Aksara.

[10] R. Novita and S. Z. Harahap, "PENGEMBANGAN MEDIA PEMBELAJARAN INTERAKTIF PADA MATA PELAJARAN SISTEM KOMPUTER DI SMK," JURNAL INFORMATIKA, vol. 8, no. 1, pp. 36-44, Jan. 2020.

[11] A. Nastuti and S. Z. Harahap, "TEKNIK DATA MINING UNTUK PENENTUAN PAKET HEMAT SEMBAKO DAN KEBUTUHAN HARIAN DENGAN MENGGUNAKAN ALGORITMA FP-GROWTH (STUDI KASUS DI ULFAMART
LUBUK ALUNG), " JURNAL INFORMATIKA, vol. 7, no. 3, pp. 111-119, Sep. 2019.

[12] Samsir and S. Z. Harahap, "APPLICATION DESIGN RESUME MEDICAL BY USING MICROSOFT VISUAL BASIC. NET 2010 AT THE HEALTH CENTER APPOINTMENTS," International Journal Of Science, Technology \& Management, vol. 1, no. 1, pp. 14-20, Jun. 2020.

[13] S. Z. Harahap and Samsir, "APPLICATION DESIGN THE DATA COLLECTION FEATURES OF THE HOTEL SHADES OF RANTAUPRAPAT USING VBNET," International Journal Of Science, Technology \& Management, vol. 1, no. 1, pp. 1-6, Jun. 2020.

[14] M. Nasution, S. Pohan, and S. Z. Harahap, "Implementasi Obrim (Option-Based Risk Management) Sebagai Framework Investasi Teknologi Informasi Perguruan Tinggi (Studi Kasus: Amik Labuhan Batu)," JURNAL INFORMATIKA, vol. 8, no. 1, pp. 26-35, Jan. 2020.

[15] S. Z. Harahap and M. H. Dar, "APLIKASI DAN PERANCANGAN SISTEM INFORMASI PEMESANAN PADA UPI CONVENTION CENTER DENGAN MENGGUNAKAN BAHASA PEMROGRAMAN PHP DAN MYSQL," JURNAL INFORMATIKA, vol. 6 , no. 3, pp. 24-27, Sep. 2019.

[16] M. H. Dar and S. Z. Harahap, "IMPLEMENTASI SNORT 
INTRUSION DETECTION

SYSTEM (IDS) PADA SISTEM JARINGAN KOMPUTER," JURNAL INFORMATIKA, vol. 6, no. 3, pp. 14-23, Sep. 2017.

[17] S. Samsir, D. Indra, G. Hts, and S. Z. Harahap, "SPK Untuk Pemilihan Kepala Sekolah Menggunakan Metode Saw dan Profile Matching," U-NET J. Tek. Inform., vol. 4, no. 1, pp. 7-12, 2020.

[18] P. Iwan, S. Z. Harahap, and A. A. Ritonga, "RANCANG BANGUN
TEMPAT SAMPAH OTOMATIS

PADA UNIVERSITAS

LABUHANBATU,"

INFORMATIKA, vol. 8, no. 2, pp. $1-5,2020$.

[19] M. Siddik and S. Z. Harahap, "UNET: Jurnal Teknik Informatika LPPM - Universitas Al Washliyah Labuhanbatu $12 \mid \mathrm{P}$ a g e U-NET: Jurnal Teknik Informatika LPPM Universitas Al Washliyah Labuhanbatu 13 | P a g e," U-NET J. Tek. Inform., vol. 3, no. 3, pp. 12-17, 2019. 